\title{
Coastal Aquatic Remote Sensing Applications for Environmental Monitoring and Management
}

\author{
Vittorio E. Brando ${ }^{a, b}$, Stuart R. Phinn ${ }^{b}$ \\ a. CSIRO Land \& Water, P.O. Box 1666, 2601, Canberra, ACT, Australia \\ vittorio.brando@csiro.au \\ b. Centre for Remote Sensing and Spatial Information Science \\ School of Geography, Planning and Architecture \\ The University of Queensland \\ Brisbane, Queensland, Australia, 4072, \\ s.phinn@uq.edu.au
}

Keywords: coastal, marine, monitoring, management, water quality, habitat, benthic cover, aquatic vegetation, algal blooms, coral, kelp, suspended sediment, chlorophyll concentration.

\section{REMOTE SENSING OF COASTAL AQUATIC ENVIRONMENTS: FOR MONITORING AND MANAGEMENT}

In all regions of the world, coastal aquatic environments are under increasing levels of environmental stress, due to the large number of people living immediately adjacent to them and using them as a resource. Information on the composition and condition of these water bodies and their benthic environments is a critical piece of knowledge infrastructure for development and application of coastal management practices [1-3]. Due to the large and dynamic nature of coastal aquatic environments, remote sensing offers a potential source for this information. However, if remote sensing is so useful and suitable data sets for mapping and monitoring coastal environments have been around since the Landsat era (1972) - why isn't it widely used in coastal resource management applications around the world?

There are a number of potential answers to that question, related to suitability of technology, methods and the communication of true costs and capabilities of remote sensing based approaches. Bukata [4] offers the following reasons for the limited "operational" use of remote sensing for monitoring coastal environments:

- Inadequate technology;

- Inadequate science;

- Inadequate or non-existent applications;

- Inadequate communication of potential, results and products;

- Lack of official standards for image products;

- $\quad$ Cost of regular delivery is too high;

- Satellite remote sensing is "suspect"; and

- Society and/or organizational barriers exist.

Very few papers, with the exception of large scale physical-biological oceanographic applications, published in scientific journals show a global uptake of the science and techniques of aquatic remote sensing into environmentally relevant monitoring and management applications. The majority of past reviews of remote sensing for coastal applications have focused on two areas: (1) improvements to technology, techniques and applications, with limited assessment of accuracy and true costs [1,3,5-11] and (2) understanding light interactions in shallow water environments $[6,12]$. Both of these activities were essential to underpin the use of remote sensing for monitoring and managing coastal resources. We are now in a position where we can: collect suitable image data; apply robust models to transform the images to maps of biophysical parameters; collect field data to 
validate the derived maps; estimate the true costs of producing the image based maps; and disseminate the data digitally via ubiquitous technology (internet and Google Earth).

A number of recent reviews have shown successful applications of remotely sensed data to a range of coastal aquatic environment management activities, and point to the direction for future applications. This was the motivation for compiling this special section as we believe there is a convergence of technology, underlying science and communications which will now allow a rapid increase in the use of remote sensing for monitoring and management related activities - if, and only if, we clearly communicate what it is we are doing and its benefits.

To fill a gap in recent literature, a special section of the Journal of Applied Remote Sensing on aquatic remote sensing applications in environmental monitoring and management was proposed. This special section contains nine papers representing the state of the art of remote sensing applications in aquatic environments (inland, estuarine and coastal waters, seagrass and coral reefs) with a focus on papers clearly demonstrating monitoring and management applications [13-21].

\section{OVERVIEW OF PAPERS IN THE SPECIAL SECTION}

Two main themes were evident from the papers, firstly, that a suitable wide range of image data sets exist with variable spatial, spectral, radiometric and temporal resolutions to meet the needs of the coastal science, monitoring and management communities. Secondly, remotely sensed data are being used on an operational basis as part of ongoing monitoring and management programs to derive essential biophysical information on water quality, algal blooms, bathymetry and benthic/substrate composition

The papers covered in the special section cover each element of the coastal aquatic zone, including: water surface and column properties, such as algal blooms [19,20 18], kelp [15], and the concentration of organic and inorganic material within the water column $[13,14,18,21]$; bathymetry $[13,14,17,21]$ and benthic/substrate cover $[16,17,21]$. Two notable advances, evident from all of these papers, and distinct from past reviews on the status of remote sensing for mapping coastal aquatic environments, are: (1) the operational use of semianalytic algorithms to estimate depth/concentrations/reflectance; along with (2) the quantification and communication of accuracy and precision of the output maps of bathymetry, benthic/substrate composition and water quality parameters. This second point is critical and continued presentation of work like this will enable potential users to clearly assess the utility of the data and techniques for their purposes.

The papers featured in this special section made use most of the available spatial, spectral, radiometric and temporal resolutions to design the monitoring and management applications. [13-15,17,21] demonstrate practical approaches for processing a variety of hyper-spectral images of optically shallow waters. The long time series of global ocean colour satellite data (i.e. AVHRR, SeaWIFS, MODIS) were used to provide quantitative maps of water constituents and their variation over seasons or several years [18-20]. Multi-spectral satellite data was used at fine spatial scale to map coral cover variations [16] and at medium scale to map suspended solids [18]

Applications were presented for either baseline monitoring and management activities. Clear demonstrations of management ready applications were presented for mapping and tracking algal blooms in the Baltic Sea [19], mapping the seasonal and spatial variations of water quality in one of the largest European fresh water bodies [20], monitoring changes in coral cover in areas subject to different management zonation and practices [16], and monitoring suspended sediment concentrations for active management of a shipping channel dredging operation [18]. Improved methods for baseline mapping and monitoring of benthic cover features were presented for coral reef and seagrass environments [13-15,17,21], for a range of environments in north-west Australia, Hawaii, Italy and Florida. These papers also 
demonstrated the value of hyper-spectral image data and semi-analytic algorithms for deriving bathymetry and water quality parameters, in addition to seafloor reflectance.

Goodman and Ustin [13] integrated a semi-analytical inversion model with a linear unmixing analysis to derive maps of depth and benthic composition from an airborne hyperspectral image for a coral reef environment in Kaneohe Bay, Hawaii.

Lee et al. [14] applied space-borne hyper-spectral imagery to deriver water quality, depth and benthic properties for a coastal environment. They developed, tested and validated a topto-bottom processing of Hyperion imagery, with no use of any a-priori or field survey information for retrieval of subsurface properties.

Volent et al. [15] present the use of airborne hyper-spectral imagery to map a Kelp forest in Polar shallow waters. The discrimination between kelp and bottom substrate was based on Bayesian supervised classification using imagery acquired with a light-weight custom built hyper-spectral imager.

Newman et al. [16] mapped the change in live coral cover between 2001 and 2004 within a Marine Protected Area in Indonesia. A supervised classification of IKONOS satellite image data was used to estimate changes within the nine different management/use zones of live coral cover, an often-used surrogate for reef health. Their results allow the discussion of the conservation-effectiveness of the zonation of the Bunaken National Park in respect the responses of the reef to diving and boating activity and other human impact.

Klonowski et al [17] describe a method for quantitatively estimating both bathymetry and benthic cover in shallow waters from airborne hyper-spectral imagery over a coral reef in north-western Australia. Their physics-based approach enabled the accurate mapping of bathymetry as well as three substrate classes.

Islam et al. [18] combined the use of long time series of global ocean colour satellite data (i.e. MODIS) with multi-spectral satellite data (Landsat 5 Thematic Mapper) to provide operational monitoring of sediment plume extent, movement and suspended solids concentrations during a dredging operation in the inshore waters of the Great Barrier Reef. . They were able to provide information which enabled understanding of plume dispersion and variations in sediment concentration due to dredging activities on a near-daily basis.

Hansson and Håkansson [19] developed a mapping and monitoring application that used satellite data to detect and monitor algal blooms in the Baltic Sea. These data were then served to the public across a website.. A supervised classifications algorithm was applied to a decade of NOAA-AVHRR data (1997-2006) to enable the mapping of cyanobacterial bloom duration, extent and intensity in the Baltic Sea.

Korosov et al. [20] presents a study of seasonal and spatial variations for water quality parameters in Lake Ladoga, one of the largest European fresh water bodies. A bio-optical algorithm was applied to seven years of SeaWIFS data to simultaneously retrieve the concentrations of three parameters (chlorophyll, suspended matter and dissolved organic matter). Their results used several animations to present the dynamics of the spatial distribution of these water quality parameters and their relationship with the temperature field.

Giardino et al. [21] evaluated the variation in submerged vegetation variation in the largest Italian lake using hyper-spectral airborne data acquired in the summers of 1997 and 2005. A physics-based approach was used to discriminate between two benthic cover types: bare sand and submerged vegetation. The benthic cover maps showed a decrease in area of macrophyte beds in Lake Garda between the two dates, which was confirmed by a point-based assessment of macrophyte distribution.

\section{CONCLUDING REMARKS}

Progression in the use of remote sensing for coastal science and resource monitoring and management is evident from the types of data, management relevant information products, processing approaches and reported accuracies presented in the papers contained in this 
section, in contrast to the technique and application focus of past reviews of remote sensing applications in coastal environments $[3,9,10]$. We have started to address the major limitations identified by Bukata [4] and Phinn et al. [10] which restricted uptake of remote sensing for operational uses. This has been enabled by an improved understanding of light interactions in shallow waters [6], coupled with more advanced computation capabilities, and spatial data dissemination capabilities offered by internet and internet/client based data viewing and analysis systems (e.g. Google-Earth, Microsoft-Virtual Earth).

A significant effort will still be needed in the future to link fundamental science through to final communications with the managers. Clear communication of the true cost, accuracy and precision of remotely sensed products for mapping these complex aquatic environments will enable scientific and non-scientific end-users to make more informed choices. We should also point out that the focus of this special section has been more on clear, shallow water coastal environments, and there is an even greater need to link these techniques with approaches more suited to shallow, turbid environments, to provide comprehensive mapping and monitoring capabilities for the coast.

\section{Acknowledgments}

We are grateful to the Editor and the editorial office of the Journal of Applied Remote Sensing to give us the opportunity and support to prepare this special section. The authors and the many anonymous reviewers contributed to make this special section possible.

\section{References}

[1] E.P. Green, P.J. Mumby, A.J. Edwards, and C.D. Clark, Remote sensing handbook for tropical coastal management, UNESCO, Paris, 2000.

[2] J. Rice, "Environmental health indicators," Ocean Coastal Manage. 46, 235-239 (2003) [doi: 10.1016/S0964-5691(03)00006-1]

[3] L. Richardson and E. Le Drew, Remote sensing of coastal aquatic ecosystem processes: Science and Management Applications, Springer, Dordrecht (2006) [doi:10.1007/1-4020-3968-9].

[4] R. P. Bukata, Satellite monitoring of inland and coastal water quality: retrospection, introspection and future directions, CRC Press/Taylor and Francis Group, Boca Raton, FL (2005).

[5] F. Dadouh-Guebas, "The use of remote sensing and GIS in the sustainable management of tropical coastal ecosystems," Environ. Develop. Sustainability 4, 93 112 (2002) [doi:10.1023/A:1020887204285].

[6] S. Ackleson, "Light in shallow waters: a brief research review," Limnol. Oceanogr. 48, 323-328 (2003).

[7] T. Malthus and P. Mumby, "Remote sensing of the coastal zone: an overview and priorities for future research," Int. J. Rem. Sens. 24, 2805-2815, (2003) [doi:10.1080/0143116031000066954].

[8] S. Andréfouët and S. Riegel, "Remote sensing: a key tool for interdisciplinary assessment of coral reef processes," Coral Reefs 23, 1-4 (2004) [doi:10.1007/s00338-003-0360-z].

[9] R. Miller, C. Del Castillo, and B. McKee, Remote Sensing of Coastal Aquatic Environments: Technologies, Techniques and Applications, Springer, Dordrecht, (2005) [doi:10.1007/978-1-4020-3100-7_11].

[10] S. Phinn, K. Joyce, P. Scarth, and C. Roelfsema, "The Role of Integrated Information Acquisition and Management in the Analysis of Coastal Ecosystem Change,"Remote 
sensing of coastal aquatic ecosystem processes: Science and Management Applications, L. Richardson and E. Le Drew, Eds., pp. 217-250, Springer, Dordrecht, (2006).

[11] A. G. Dekker, V. Brando, J. Anstee, S. Fyfe, T. Malthus, E. Karpouzli, A. W. D. Larkum, R. J. Orth, and C. M. Duarte, "Remote sensing of seagrass ecosystems: Use of spaceborne and airborne sensors," Seagrasses: Biology, Ecology and Conservation, pp. 347-359, Springer, (2006).

[12] A. G. Dekker, V. E. Brando, J. M. Anstee, N. Pinnel, T. Kutser, E. J. Hoogenboom, S. Peters, R. Pasterkamp, R. Vos, C. Olbert, and T. J. M. Malthus, Imaging spectrometry of water, Imaging Spectrometry: Basic Principles and Prospective Applications, pp. 307-359 (2001).

[13] J. Goodman and S. L. Ustin, "Classification of benthic composition in a coral reef environment using spectral unmixing," J. Appl. Rem. Sens. 1, 011501 (2007) [doi: 10.1117/1.2815907].

[14] Z. Lee, B. Casey, R. Arnone, A. Weidemann, R. Parsons, M. J. Montes, B.-C. Gao, W. Goode, C. O. Davis, and J. Dye, "Water and bottom properties of a coastal environment derived from Hyperion data measured from the EO-1 spacecraft platform," J. Appl. Rem. Sens. 1, 011502 (2007) [doi: 10.1117/1.2822610].

[15] Z. Volent, G. Johnsen, and F. Sigernes, "Kelp forest mapping by use of airborne hyperspectral imager" J. Appl. Rem. Sens. 1, 011503 (2007) [doi: 10.1117/12822611].

[16] C. M. Newman, A. J. Knudby, and E. F. LeDrew, "Assessing the effect of management zonation on live coral cover using multi-date IKONOS satellite imagery," J. Appl. Rem. Sens. 1, 011504 (2007) [doi: 10.1117/1.2822612].

[17] W. M. Klonowski, P. R. C. S. Fearns, and M. J. Lynch, "Retrieving key benthic cover types and bathymetry from hyperspectral imagery," J. Appl. Rem. Sens. 1, 011505 (2007) [doi: 10.1117/1.2816113].

[18] A. Islam, L. Wang, C. Smith, S. Reddy, A. Lewis, and A. Smith, "Evaluation of satellite remote sensing for operational monitoring of sediment plumes produced by dredging at Hay Point, Queensland, Australia," J. Appl. Rem. Sens. 1, 011506 (2007) [doi: 10.1117/1.2834768].

[19] M. Hansson and B. Håkansson, "Baltic algae watch system - a remote sensing application for monitoring cyanobacterial blooms in the Baltic Sea," J. Appl. Rem. Sens. 1, 011507(2007) [doi: 10.117/1.2834769].

[20] A. Korosov, D. V. Pozdnyakov, L. H. Pettersson, and H. Grassl, "A satellite data based study of seasonal and spatial variations of some ecoparameters in Lake Ladoga," J. Appl. Rem. Sens. 1, 011508 (2007) [doi: 10.117/1.2834770].

[21] C. Giardino, M. Bartoli, G. Candiani, M. Bresciani, and L. Pellegrini, "Recent changes in macrophyte colonisation patterns: an imaging spectrometry-based evaluation of the southern Lake Garda (northern Italy)," J. Appl. Rem. Sens. 1, 011509 (2007) [doi: 10.1117/1.2834807].

Vittorio E. Brando is a Research Scientist in the Environmental Remote Sensing Group of CSIRO Land \& Water in Canberra, Australia. He received a "laurea" degree cum laude in environmental sciences at the University of Venice, Italy in 1995 and a $\mathrm{PhD}$ in environmental systems modeling at the University of Padua, Italy in 2000. His current research is focused on remote sensing of coastal waters with the aim of enabling a better understanding of environmental processes of coastal systems, and on the translation of the remote sensing data into relevant information for decision makers or other scientific and non scientific end-users. 
Stuart R. Phinn runs the Centre for Remote Sensing and Spatial Information Science (www.gpa.uq.edu.au/CRSSIS/ ) and coordinates undergraduate and postgraduate remote sensing courses at the University of Queensland. His research and student project work focus on developing remote sensing applications for monitoring environmental conditions in a range of aquatic, wetland and terrestrial environments. 